\title{
Genetic risks associated with advanced assisted reproductive technology
}

\author{
Peter TK Chan MD
}

PTK Chan. Genetic risks associated with advanced assisted reproductive technology. J Sex Reprod Med 2002;2(4):161-164.

Advanced assisted reproductive technologies such as in vitro fertilization (IVF) and intracytoplasmic sperm injection (ICSI) are established treatment for severe male-factor infertility. The risk of transmitting existing genetic abnormalities to offspring through assisted reproduction has been a particular concern in male infertility cases due to Y-chromosome microdeletion, congenital bilateral absence of the vas deferens and Klinefelter's syndrome, because these conditions generally required ICSI to achieve pregnancy. In addition, earlier studies raised the concerns of increased spontaneous abortion rate and chromosomal abnormalities with IVF and ICSI. Recently, well designed, large scale, population based studies concluded that assisted reproductive technology accounts for a more than a two-fold increase in the risk of low birth weight and major birth defects. Taken together, the bulk of the literature on the genetic risks of assisted reproduction highlights the importance of adequate pretreatment genetic evaluation and counselling. Furthermore, it is important to have proper infertility evaluation to identify and treat reversible causes of male-factor infertility that would allow couples to conceive naturally or opt for less invasive assisted reproductive technology.

Key Words: Assisted reproduction; Azoospermia; Congenital malformation; Genetics; ICSI; Male infertility

\section{Risques génétiques liés aux techniques de reproduction assistée de pointe}

RÉSUMÉ : Les techniques de reproduction assistée (TRA) de pointe comme la fécondation in vitro (FIV) et l'injection intracytoplasmique de spermatozoïdes (IICS) constituent des traitements reconnus des formes graves d'infertilité masculine. Le risque de transmission des anomalies génétiques existantes par la reproduction assistée soulève des craintes particulières dans les cas d'infertilité masculine attribuable à la microdélétion du chromosome $Y$, à l'absence bilatérale congénitale des canaux déférents et au syndrome de Klinefelter, parce que ces troubles nécessitent tous généralement le recours à l'IICS pour provoquer une grossesse. D'ailleurs, des études ont déjà fait état de taux accrus d'anomalies chromosomiques et d'avortements spontanés liés à la FIV et à l'IICS. Selon des études récentes fondées sur des populations, bien structurées et menées à grande échelle, les TRA font plus que doubler le risque d'insuffisance de poids à la naissance et d'anomalies congénitales sérieuses. Dans l'ensemble, la documentation sur les risques génétiques liés à la reproduction assistée fait ressortir l'importance d'une bonne évaluation génétique et d'une consultation appropriée avant le traitement. Enfin, il est important de procéder à une évaluation adéquate de l'infertilité masculine afin de déceler et de traiter les causes réversibles, ce qui permettrait aux couples de concevoir naturellement un enfant ou de choisir des TRA moins effractives.

\footnotetext{
A ssisted reproduction with in vitro fertilization (IVF) and intracytoplasmic sperm injection (ICSI) has been increasing in popularity due to its effectiveness and our increasing experience in its indications and limitations. In addition to some female-factor infertility, IVF and ICSI are indicated in couples with severe male-factor infertility that is irreversible or not amenable to other forms of treatment. Genetic risk in offspring of IVF and ICSI pregnancies has been a concern for the following reasons: the in vitro mech-
}

anism in selecting or eliminating abnormal sperm may not be as rigorous as in vivo; physical injury to gametes, such as damage to the meiotic spindle, is known to occur; transmission of gene(s) that cause spermatogenic failure may lead to offspring having somatic anomalies; altered hormonal milieu and gamete manipulation may result in delayed DNA replication, point mutation or impaired meiosis or mitosis; and chromosomal abnormalities (despite a normal somatic karyotype) are found at a higher rate in sperm from 
men with severe oligospermia and azoospermia (1). In the present article, we review evidence in the literature on the actual genetic risk of assisted reproduction.

\section{TRANSMISSION OF EXISTING GENETIC ABNORMALITIES THROUGH ASSISTED REPRODUCTION}

Obviously, existing genetic conditions of the parents can be transmitted to the offspring through assisted reproduction, as they would with natural conception, if feasible. Three genetic conditions of special relevance to male-factor infertility are microdeletion of the Y-chromosome, congenital bilateral absence of the vas deferens (CBAVD) and Klinefelter's syndrome.

The frequency of microdeletion of the Y-chromosome in severely oligospermic and azoospermic men is approximately $5 \%$ to $21 \%$. In the absence of azoospermia factor a (AZFa) or complete azzospermia factor $\mathrm{b}(\mathrm{AZFb})$ deletion, where mature spermatozoa are virtually never found, these patients can have ICSI as a treatment option, with a success rate of testicular sperm retrieval not significantly different from other nonobstructive azoospermic men. All male offspring, however, will have Y-chromosome microdeletion, though the phenotypical impact may not necessarily be identical to that on the father, due to the possibility of further expansion of the deletion, gene pleiotropism and the presence of similar autosomal genes that may exhibit some functional redundancy. In fact, male offspring with this microdeletion will inherit infertility from their father. On the other hand, female offspring will not inherit AZF deletion. Interestingly, the sex ratio in offspring of these men is normal (ie, equal chance of selecting a sperm with an $\mathrm{X}$ or $\mathrm{Y}$ chromosome for ICSI), indicating an absence of interference in gamete meiosis by the presence of Y-chromosome microdeletion.

ICSI is virtually the only fertility treatment option available for men with CBAVD. Although these men generally have obstructive azoospermia (ie, normal spermatogenesis in the testis), surgical reconstruction of the excurrent ductal system is rarely feasible. CBAVD is due to mutations of the cystic fibrosis transmembrane regulator (CFTR) gene and is considered to be a 'genital form' of cystic fibrosis. Cystic fibrosis is the most common fatal autosomal recessive disorder in white people, with an incidence of approximately one in 2400 live births and a carrier frequency of one in 25 persons of northern European descent. Two dysfunctional alleles are required for the person to have the condition. There are currently more than 1000 known mutations in the CFTR gene, the most common one being delta-F508 mutation, appearing in about $75 \%$ of people affected with cystic fibrosis in North America. Men with CBAVD should be screened for CFTR mutation, because $50 \%$ to $80 \%$ of them are carriers of at least one known CFTR gene mutation, while around $10 \%$ have two. In addition, the female partner should also be screened for CFTR mutation, although the likelihood of detecting a mutation depends on the woman's ethnic background. Screening is generally performed for as least the most common 25 muta- tions (Table 1). When counselling these couples, it should be emphasized that even in the absence of a detectable mutation from a screening test, there may still be a risk of cystic fibrosis or related phenotype, because less common mutations that are not in the screening test panel may be present.

Men with nonmosaic Klinefelter's syndrome may achieve pregnancy with ICSI. The overall success in testicular sperm retrieval in the literature is about $56 \%$, similar to the success rate in other nonobstructive azoospermic men (2). Over 11 pregnancies with more than 16 healthy neonates have been reported following ICSI with spermatozoa from men with nonmosaic Klinefelter's syndrome. Interestingly, sperm of nonmosaic men with Klinefelter's syndrome (with $47 \mathrm{XXY}$ ) rarely display hyperhaploidy (eg, disomy $24 \mathrm{XY}$ or $24 \mathrm{XX}$ ). In fact, approximately $1 \%$ to $3.4 \%$ of these sperm are $24 \mathrm{XY}$, a rate that is higher than that in infertile $(1 \%)$ and fertile men $(0.2 \%)$ but is significantly lower than the theoretical $25 \%$ to $50 \%$. In addition to proper genetic counselling, preimplantation genetic diagnosis on embryos should be used to avoid sex chromosomal and autosomal aneuploidy and embryo abnormalities, which are demonstrated to occur at increased rates in men with Klinefelter's syndrome $(1,3)$.

\section{SPONTANEOUS ABORTION RATE WITH IVF AND ICSI}

The spontaneous abortion rate in IVF pregnancies not requiring ICSI is $18.1 \%$ (4). With ICSI, one study in the United States reported a spontaneous abortion rate of $17.5 \%$ in more than 6000 cycles (5). On the contrary, the rate of spontaneous pregnancy loss in the general population is only $10 \%$ to $12 \%$. While a higher rate of chromosomal abnormalities from IVF and ICSI (see "Chromosomal abnormalities after IVF and ICSI", below) contributing to the observed increase in spontaneous abortion rate is speculated, there is no definitive evidence available in the literature to support it. On the other hand, the apparent increase in spontaneous abortion rate could be due to the more rigorous and longer length of observation in IVF and ICSI pregnancies, in which surveillance generally begins at conception. Pregnancy losses in such a setting would go unrecognized rarely, if ever. Finally, the validity of a comparison to the general population is questionable, because often there is the presence of male-factor infertility and the maternal age is usually more advanced in couples requiring IVF and ICSI.

\section{CHROMOSOMAL ABNORMALITIES AFTER IVF AND ICSI}

Based on the results from various studies, the general consensus is that the chromosomal abnormality rate in ICSI pregnancies is increased compared with a control neonatal population, particularly with respect to sex chromosomes, but also structural de novo aberrations $(6,7)$. The actual increase is generally no more than $1 \%$ over the baseline rate (Table 2) (6-9). Several mechanisms may be involved in 
TABLE 1

Common cystic fibrosis transmembrane regulator mutations for carrier screening

\begin{tabular}{lllll}
\hline$\Delta \mathrm{F} 508$ & $\mathrm{D} 1507$ & G542X & G551D & W1282X \\
$\mathrm{N} 1303 \mathrm{~K}$ & $\mathrm{R} 553 \mathrm{X}$ & $621+1 \mathrm{G} \rightarrow \mathrm{T}$ & $1717-1 \mathrm{G} \rightarrow \mathrm{A}$ & A455E \\
$\mathrm{R} 560 \mathrm{~T}$ & $\mathrm{R} 1162 \mathrm{X}$ & $\mathrm{G} 85 \mathrm{E}$ & $\mathrm{R} 334 \mathrm{~W}$ & $\mathrm{R} 347 \mathrm{P}$ \\
$711+1 \mathrm{G} \rightarrow \mathrm{T}$ & $1898+1 \mathrm{G} \rightarrow \mathrm{A}$ & $2184 \mathrm{delA}$ & $1078 \mathrm{delT}$ & $3849+10 \mathrm{kbc} \rightarrow \mathrm{T}$ \\
$2789+5 \mathrm{G} \rightarrow \mathrm{A}$ & 3659delC & I148T & $3120+1 \mathrm{G} \rightarrow \mathrm{A}$ & $\mathrm{R} 117 \mathrm{H}$ \\
\hline
\end{tabular}

\section{TABLE 2}

\begin{tabular}{|c|c|c|}
\hline Chromosomal abnormalities & $\mathbf{n}$ & Percentage \\
\hline \multicolumn{3}{|l|}{ De Novo } \\
\hline Sex chromosomal & 9 & $0.83 \%$ \\
\hline Autosomal & 9 & $0.82 \%$ \\
\hline Aneuploidy & 4 & $0.36 \%$ \\
\hline Structural & 5 & $0.46 \%$ \\
\hline Inherited & 10 & $0.92 \%$ \\
\hline Balanced & 9 & $0.83 \%$ \\
\hline Unbalanced & 1 & $0.09 \%$ \\
\hline Total & 28 & $2.57 \%$ \\
\hline
\end{tabular}

Data from references 8 and 9

the increased frequency of chromosomal abnormalities following ICSI. Damage to gametes from the procedure, leading to meiotic spindle disruption or delayed DNA replication, have been reported. In addition, the frequency of somatic chromosome abnormalities appears to correlate inversely with the spermatogenic potential of the testes (10), with a frequency as high as $18.7 \%$ in azoospermic men but only $2.4 \%$ in mild or moderate oligospermic men (Table 3 ). Furthermore, testicular sperm in men with severe oligospermia or azoospermia are known to exhibit an increased incidence in sex chromosome nondisjunction. Even mature sperm from the ejaculate in oligospermic men with normal somatic karyotype have shown an increased frequency of sex chromosome abnormalities (11).

\section{CONGENITAL ANOMALIES IN IVF AND ICSI}

Studies designed to determine whether anomaly rates are increased in IVF and ICSI pregnancies are subject to similar pitfalls from confounding variables mentioned previously. More extensive neonatal examination following IVF and ICSI pregnancies compared with natural ones may be implemented. For instance, minor anomalies recorded in surveys of IVF and ICSI pregnancies may not be recorded consistently in general surveys of natural pregnancies. Routine examination by obstetricians untrained in neonatal examination may fail to detect minor anomalies. Furthermore, surveillance with obstetric ultrasonogram may be more rigorous in the IVF and ICSI group, leading to a higher rate of detection of internal anomalies, which, in
TABLE 3

Association of somatic chromosomal abnormalities and semen spermatozoa concentration

\begin{tabular}{lc}
\hline $\begin{array}{l}\text { Sperm concentration } \\
(\mathbf{1 0} \text { sperm/mL) }\end{array}$ & $\begin{array}{l}\text { Frequency of } \\
\text { chromosomal } \\
\text { abnormalities }\end{array}$ \\
\hline Azoospermia & $18.7 \%$ \\
Severe oligospermia (0-5) & $4.6 \%$ \\
Mild to moderate oligospermia (5-20) & $2.8 \%$ \\
Normospermia (>20) & $3.0 \%$ \\
Total & $6.11 \%$ \\
\hline
\end{tabular}

Data from reference 10

the absence of associated external anomalies, may not be discovered in natural pregnancies.

Notwithstanding the aforementioned pitfalls, the bulk of studies in the past decade did not demonstrate an increase in the rate of congenital anomalies with IVF and ICSI (1). The reported rate of anomalies in these studies ranges from $1 \%$ to $4 \%$. Although the overall rate of anomalies did not seem to increase with reproductive technologies, some specific defects appeared to be significantly more prevalent in IVF and ICSI pregnancies. Neural tube defects were found with up to a threefold increase with IVF (12). With ICSI, hypospadias was found to increase in offspring (13).

While the finding of no increase in the rate of congenital malformation with assisted reproductive technology is reassuring, many researchers criticized the methodology, particularly the inadequacy of sample size and the lack of appropriate controls for valid comparison. One recent study designed to address the major methodological problems of previous research concluded that infants conceived with IVF and ICSI have twice as high a risk of major birth defects as naturally conceived infants (9.0\% versus $4.2 \%)$ (14). Such an increase in the risk remained significant even when only singleton or term singleton infants were considered, as well as after adjustment for maternal age, parity, sex of the infant and correlation between siblings.

Various factors may contribute to the increase in the risk of congenital anomalies with assisted reproductive technology: relatively advanced age of the infertile couples; underlying cause of infertility; teratogenic effects of exogenously administered medications for ovulation induction and pregnancy maintenance in the early stages; and, finally, factors associated with the assisted reproduction procedures them- 
selves, including the freezing and thawing of embryos, the potential for polyspermic fertilization and the delayed fertilization of the oocyte. The consideration that the use of assisted reproduction technology may increase the chance of unfavourable neonatal outcomes, irrespective of parental factors, raises particular concerns about the safety of these procedures. A recent study from the United States concluded that assisted reproductive technology accounts for a 2.6fold increase in the risk of low birth weight $(6.5 \%$ versus $2.5 \%)$ in term singletons (15). Such an increase was not explained by factors such as maternal age, parity, gestational age, multiplicity and parental fertility status, suggesting that the increased risk of low birth weight is directly related to assisted reproductive technology.

\section{SIGNIFICANCE TO CLINICIANS}

From the various studies in the past decade that looked at the genetic effects of assisted reproduction on offspring, it is apparent that the risk of unfavourable neonatal outcomes is realistic. Because ICSI has been performed for only 10 years, ongoing efforts in investigations are required to further define the extent of such risks in various groups of infertile couples. These findings will help infertile couples to evaluate the risks that they and their offspring may face if they choose to use assisted reproductive technology.

In the United States, the number of in vitro fertilization procedures increased by 37\% between 1995 and 1998. With the growing numbers of fertility specialists and private clinics in the recent years, competition for clients will likely be more aggressive. The availability of effective advanced assisted reproductive technology is not a reason to bypass efforts in proper diagnosis and treatment of the etiology of infertility for infertile couples. Thorough investigations and proper treatment for reversible causes of infertility may allow couples to conceive naturally or opt for less invasive assisted reproductive technology, thereby potentially reducing the genetic risks in their offspring, along with the financial burdens, stress and other health risks associated with IVF and ICSI.

On the other hand, for couples in whom advanced assisted reproduction is the only feasible option, IVF and ICSI remain an effective option. The absolute genetic risk is more important than the relative risk when providing counselling to these couples. Although the use of IVF and ICSI significantly increases the genetic risk, the majority of couples who require assistance with reproduction will not be affected. In other words, while an increase of congenital anomalies from $4 \%$ to $9 \%$ is significant, one must also realize that the likelihood of having an infant free of anomalies decreases from $96 \%$ to $91 \%$, a risk that many couples who are otherwise unable to have biological children may be willing to accept. It must, however, be emphasized that this decision should be made by the couples on a case by case basis.

\section{REFERENCES}

1. Simpson JL, Lamb DJ. Genetic effects of intracytoplasmic sperm injection. Seminars in Reprod Med 2001;19:239-49.

2. Friedler S, Raziel A, Strassburger D, Schachter M, Bern O, Ron-El R. Outcome of ICSI using fresh and cryopreserved-thawed testicular spermatozoa in patients with non-mosaic Klinefelter's syndrome. Hum Reprod 2001;16:2616-20.

3. Hennebicq S, Pelletier R, Bergues U, Rousseaux S. Risk of trisomy 21 in offspring of patients with Klinefelter's syndrome. Lancet 2001;357:2104-5.

4. Simpson JL. Are anomalies increased after ART and ICSI? In: Kempers RD, Cohen J, Haney AF, Younger BJ, eds. Fertility and Reproductive Medicine (Proceedings of the XVI World Congress on Fertility and Sterility, San Francisco). Amsterdam: Elsevier Science 1998;199-209.

5. ASRM/SART. Assisted reproductive technology in the United States: 1997 results generated from the American Society for Reproductive Medicine/Society for Assisted Reproductive Technology Registry. Fertil Steril 2000;74:641-54.

6. Van Steirteghem A, Bonduelle M, Devroey P, Liebaers I. Follow-up of children born after ICSI. Hum Reprod Update 2002;8:111-6.

7. Van Steirteghem, A, Devroey P, Liebaers I. Intracytoplasmic sperm injection. Mol Cell Endo 2002;186:199-203.

8. Bonduelle M, Aytoz A, VanAssche E, Devroey P, Liebaers I, Van Steirteghem A. Incidence of chromosomal aberrations in children

born after assisted reproduction through intracytoplasmic sperm injection. Hum Reprod 1998;13:781-2.

9. Bonduelle M, Camus M, Devos A, et al. Seven years of intracytoplasmic sperm injection and follow-up of 1987 subsequent children. Hum Reprod 1999;14(suppl 1):243-64.

10. Gekas J, Thepot F, Turleau C, et al. Chromosomal factors of infertility in candidate couples for ICSI: an equal risk of constitutional aberrations in women and men. Hum Reprod 2001;16:82-90.

11. Palermo GD, Colombero LT, Hariprashad JJ, Schlegel PN, Rosenwaks Z. Chromosome analysis of epididymal and testicular sperm in azoospermic patients undergoing ICSI. Hum Reprod 2002;17:570-5.

12. Ericson A, Kallen B. Congenital malformations in infants born after IVF: a population-based study. Hum Reprod 2001;16:504-9.

13. Wennerholm UB, Bergh C, Hamberger L, Westlander G, Wikland M, Wood M. Incidence of congenital malformations in children born after ICSI. Hum Reprod 2000;15:944-8.

14. Hansen M, Kurinczuk JJ, Bower C, Webb S. The risk of major birth defects after intracytoplasmic sperm injection and in vitro fertilization. N Engl J Med 2002;346:725-30.

15. Schieve LA, Meikle SJ, Ferre C, Peterson HB, Jeng G, Wilcox LS. Low and very low birth weight in infants conceived with use of assisted reproductive technology. N Engl J Med 2002;346:731-7. 